\title{
[6]-Shogaol inhibits melanogenesis in B16 mouse melanoma cells through activation of the ERK pathway
}

\author{
Cheng $\mathrm{YAO}^{1,2,3}$, Jang-hee $\mathrm{OH}^{1,2,3}$, Inn Gyung $\mathrm{OH}^{1,2,3}$, Chi-hyun $\mathrm{PARK}^{1,2,3, *}$, Jin Ho CHUNG ${ }^{1,2,3, *}$ \\ ${ }^{1}$ Department of Dermatology, Seoul National University College of Medicine, Seoul 110-744, Korea; ${ }^{2}$ Institute of Dermatological \\ Science, Medical Research Center, Seoul National University, Seoul 110-744, Korea; ${ }^{3}$ Laboratory of Cutaneous Aging Research, \\ Biomedical Research Institute, Seoul National University Hospital, Seoul 110-744, Korea
}

\begin{abstract}
Aim: To investigate the effect of [6]-shogaol, an active ingredient in ginger, on melanogenesis and the underlying mechanisms. Methods: B16F10 mouse melanoma cells were tested. Cell viability was determined with the MTT assay. Melanin content and tyrosinase activity were analyzed with a spectrophotometer. The protein expression of tyrosinase and microphthalmia associated transcription factor (MITF), as well as phosphorylated or total ERK1/2 and Akt were measured using Western blot.

Results: Treatment of the cells with [6]-shogaol $(1,5,10 \mu \mathrm{mol} / \mathrm{L})$ reduced the melanin content in a concentration-dependent manner. [6]-Shogaol (5 and $10 \mu \mathrm{mol} / \mathrm{L})$ significantly decreased the intracellular tyrosinase activity, and markedly suppressed the expression levels of tyrosinase and MITF proteins in the cells. Furthermore, [6]-shogaol (10 $\mathrm{mol} / \mathrm{L})$ activated ERK, which was known to negatively regulate melanin synthesis in these cells. Pretreatment with the specific ERK pathway inhibitor PD98059 (20 $\mu \mathrm{mol} / \mathrm{L})$ greatly attenuated the inhibition of melanin synthesis by [6]-shogaol $(10 \mu \mathrm{mol} / \mathrm{L})$.

Conclusion: The results demonstrate that [6]-shogaol inhibits melanogenesis in B16F10 mouse melanoma cells via activating the ERK pathway.
\end{abstract}

Keywords: [6]-shogaol; skin pigmentation; melanin; tyrosinase; MITF; ERK; B16F10 mouse melanoma cell

Acta Pharmacologica Sinica (2013) 34: 289-294; doi: 10.1038/aps.2012.134; published online 5 Nov 2012

\section{Introduction}

Melanin is a dark biological pigment that determines the color of human hair, skin, and eyes. Melanin is synthesized in melanosomes, and transferred from melanocytes to keratinocytes $^{[1]}$. Melanin production is mainly controlled by the expression and activity of tyrosinase, which is known to be the most essential enzyme involved in melanin synthesis. Tyrosinase regulates two catalytic processes: hydrolysis of tyrosine to L-DOPA, and oxidation of DOPA to DOPA quinine ${ }^{[2,3]}$. In addition, it is well-known that microphthalmia-associated transcription factor (MITF) strongly up-regulates the expression of tyrosinase and other melanogenic enzymes, such as tyrosinase-related protein 1 (TRP1) and tyrosinase-related protein 2 (TRP2) $)^{[4-6]}$.

It has been reported that skin pigmentation is regulated

\footnotetext{
* To whom correspondence should be addressed.

E-mail chppark@hotmail.com (Chi-hyun PARK); jhchung@snu.ac.kr (Jin Ho CHUNG)

Received 2012-04-28 Accepted 2012-08-26
}

by a variety of intrinsic and extrinsic factors ${ }^{[7,8]}$, as well as diverse signaling pathways including protein kinase A (PKA), phosphatidylinositol 3-kinase (PI3K), and mitogen-activated protein kinases $(\mathrm{MAPKs})^{[9-13]}$. In particular, the MAPK kinase (MEK)/extracellular signal-regulated kinase (ERK) and the PI3K/Akt pathways have been shown to negatively regulate melanin synthesis in melanocytes and melanoma cells ${ }^{[14-18]}$.

Currently, cosmetic products possessing whitening effects occupy a large proportion of the cosmetic market and have become more popular than ever in Asia. Therefore, much effort has been directed at the search for novel and effective whitening agents. As a result of melanin biosynthesis studies, kojic acid, arbutin, and many other natural products are now utilized selectively for the treatment of hyperpigmentation diseases in humans, such as melasma, freckling, and other dermatological disorders ${ }^{[19,20]}$. However, the recent discovery of their adverse side effects suggests that the applicability of these chemicals might be limited. It has been reported that kojic acid can cause allergic contact dermatitis ${ }^{[21]}$ and that arbutin might carry carcinogenic risks ${ }^{[22]}$. Moreover, low stabili- 
ties or high costs of available agents may also be issues of concern. Therefore, there is a need for development of alternative inhibitors of melanogenesis that are safer and more effective than existing agents.

[6]-Shogaol, an active ingredient in ginger, was previously reported to possess anti-cancer and anti-inflammatory properties $^{[23,24]}$. However, despite many published reports, the effect of [6]-shogaol on melanogenesis is unknown. In this study, we show the anti-melanogenic activity of [6]-shogaol in B16 mouse melanoma cells and elucidate the molecular events involved in the process.

\section{Materials and methods Materials}

[6]-Shogaol, 3-(4,5-dimethylthiazol-2-yl)-2,5-diphenyltetrazolium bromide (MTT), L-DOPA, kojic acid, and mushroom tyrosinase were purchased from Sigma-Aldrich Co (St Louis, MO, USA). PD98059 was purchased from Calbiochem (San Diego, CA, USA). Antibodies specific to phospho-ERK1/2 (Thr202/Tyr204, \#9101S), total ERK1/2 (\#9102), phospho-Akt (Ser473, \#9271), and total Akt (\#9272) were from Cell Signaling Technology (Beverly, MA, USA). Antibodies specific to tyrosinase (C-19) and $\beta$-actin (I-19) were from Santa Cruz Biotechnology, Inc(Santa Cruz, CA, USA). MITF antibody (C5, MS-771-P0) was purchased from NeoMarkers (Fremont, CA, USA). B16F10 mouse melanoma cells were obtained from the Korean Cell Line Bank (Seoul, Korea). [6]-Shogaol, kojic acid, and PD98059 were dissolved in dimethylsulphoxide (DMSO).

\section{Cell culture}

B16F10 mouse melanoma cells were cultured in phenol red-free Dulbecco's modified Eagle's media (DMEM), supplemented with glutamine $(2 \mathrm{mmol} / \mathrm{L})$, penicillin $(400 \mathrm{U} / \mathrm{mL})$, streptomycin $(50 \mathrm{~g} / \mathrm{L})$, and $10 \% \mathrm{FBS}$ at $37^{\circ} \mathrm{C}$ in a humidified atmosphere containing $5 \% \mathrm{CO}_{2}$.

\section{Cell viability assay}

Cell viabilities were determined using an MTT-based assay. After incubation of cells with [6]-shogaol for $48 \mathrm{~h}$, MTT (dissolved in PBS to $0.5 \mathrm{~g} / \mathrm{L}$ ) was then added. The cells were then incubated for an additional $2 \mathrm{~h}$; the supernatant was removed and DMSO was added to dissolve the formazan crystals. Absorbance was measured at $570 \mathrm{~nm}$ using a spectrophotometer.

\section{Measurement of melanin content}

Melanin content was measured using a previously described method with slight modifications ${ }^{[2]}$. B16 cells were incubated overnight with DMEM (phenol red-free) containing 10\% FBS at a density of $3 \times 10^{5}$ cells in $60-\mathrm{mm}$ dishes. Cells were then treated with different chemicals for $4 \mathrm{~d}$. After the treatment, $200 \mu \mathrm{L}$ aliquots of media were placed in 96-well plates and optical densities (ODs) were measured at $405 \mathrm{~nm}$ using an ELISA reader. Cells were then scraped from the dishes and their protein concentrations were determined using the Bradford assay (Bio-Rad, Hercules, CA, USA). Relative melanin production was calculated by normalizing the OD values with the protein concentrations (absorbance/ $\mu \mathrm{g}$ protein).

\section{Tyrosinase activity}

The effect of [6]-shogaol on the intracellular tyrosinase activity was determined as previously described ${ }^{[26]}$ with slight modifications. Cells were incubated with [6]-shogaol for $48 \mathrm{~h}$, washed with ice-cold PBS, and lysed with phosphate buffer (pH 6.8) containing $1 \%$ Triton X-100. After centrifuging at $13000 \mathrm{r} / \mathrm{min}$ for $10 \mathrm{~min}$, supernatants were collected. Following quantification of protein levels using the Bradford assay and adjustment of concentrations with the lysis buffer, $90 \mu \mathrm{L}$ of each lysate and $10 \mu \mathrm{L}$ of $10 \mathrm{mmol} / \mathrm{L} \mathrm{L}-\mathrm{DOPA}$ were combined in a well of a 96-well plate. Control wells contained $90 \mu \mathrm{L}$ of lysis buffer and $10 \mu \mathrm{L}$ of L-DOPA. Absorbance was measured at $475 \mathrm{~nm}$ using an ELISA reader after incubating the plate at $37^{\circ} \mathrm{C}$ for $15 \mathrm{~min}$.

The direct effect of [6]-shogaol on tyrosinase activity was determined by a cell-free assay system using mushroom tyrosinase ${ }^{[26]}$. Seventy microliters of phosphate buffer containing [6]-shogaol or kojic acid were mixed with $20 \mu \mathrm{L}$ of $10 \mathrm{~g} / \mathrm{L}$ mushroom tyrosinase, followed by the addition of $10 \mu \mathrm{L}$ of 10 $\mathrm{mmol} / \mathrm{L} \mathrm{L-DOPA}$. Following incubation at $37^{\circ} \mathrm{C}$ for $15 \mathrm{~min}$, absorbance was measured at $475 \mathrm{~nm}$.

\section{Western blot analysis}

Cells were lysed in cell lysis buffer $(20 \mathrm{mmol} / \mathrm{L}$ Tris- $\mathrm{HCl}[\mathrm{pH}$ 7.5], $150 \mathrm{mmol} / \mathrm{L} \mathrm{NaCl}, 1 \mathrm{mmol} / \mathrm{L}$ EDTA, $1 \mathrm{mmol} / \mathrm{L}$ EGTA, $1 \%$ Triton X-100, $2.5 \mathrm{mmol} / \mathrm{L}$ sodium pyrophosphate, 1 $\mathrm{mmol} / \mathrm{L} \beta$-glycerophosphate, $1 \mathrm{mmol} / \mathrm{L} \mathrm{Na}_{3} \mathrm{VO} 4,1 \mathrm{mmol} / \mathrm{L}$ dithiothreitol, $0.01 \mathrm{~g} / \mathrm{L}$ leupeptin, $0.01 \mathrm{~g} / \mathrm{L}$ aprotinin, and 1 $\mathrm{mmol} / \mathrm{L}$ PMSF). Approximately 20 to $30 \mu \mathrm{g}$ of protein per lane was separated by SDS-polyacrylamide gel electrophoresis and transferred onto PVDF membranes, which were then saturated with $5 \%$ dry milk in Tris-buffered saline containing $0.4 \%$ Tween 20. The membranes were incubated with the appropriate primary antibodies at a dilution of 1:1000, followed by further incubation with horseradish peroxidase-conjugated secondary antibodies. Antibody-bound proteins were visualized by enhanced chemiluminescence (Amersham Bioscience, Buckinghamshire, UK).

\section{Statistical analysis}

Statistical significance was determined using Student's $t$-test. The results are presented as the mean value \pm SEM. A $P$ value less than 0.05 was considered to be statistically significant.

\section{Results}

[6]-Shogaol inhibits melanin synthesis in B16 mouse melanoma cells without cytotoxicity

To determine whether [6]-shogaol has a cytotoxic effect, we treated B16 mouse melanoma cells with [6]-shogaol at the indicated concentrations for $4 \mathrm{~d}$ and checked cell viabilities using an MTT-based assay. [6]-Shogaol showed very little cytotoxicity at the concentration range of 1 to $10 \mu \mathrm{mol} / \mathrm{L}$ (Figure 1A). Melanin content was then measured in the B16 cells under the 
A

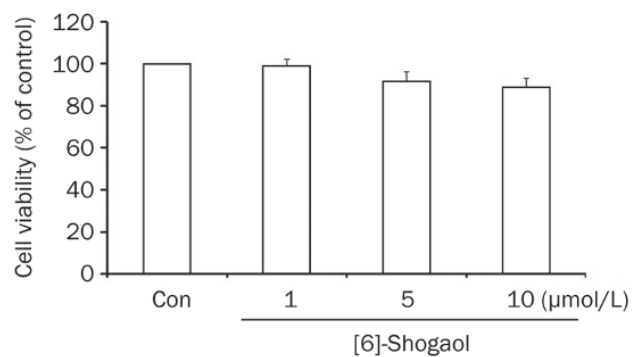

B

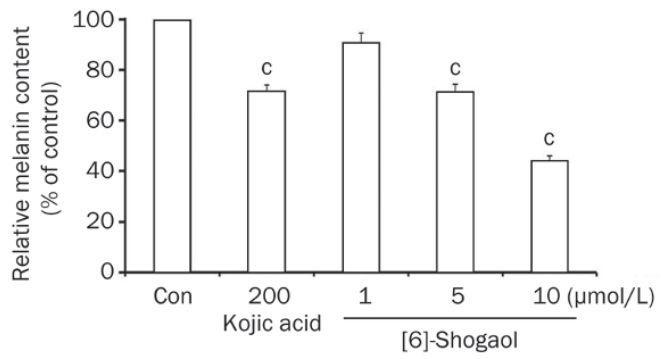

Figure 1. Effects of [6]-shogaol on cell viability and melanin content in B16 mouse melanoma cells. B16 cells were treated with [6]-shogaol at the indicated concentrations. (A) Cell viabilities were measured using an MTT-based assay at $4 \mathrm{~d}$ after treatment. (B) Relative melanin content was measured at $4 \mathrm{~d}$ after treatment. Kojic acid was used as a positive control. Con, DMSO-only vehicle control. Data are reported as the mean \pm SEM of three independent experiments carried out in triplicate. ${ }^{\mathrm{b}} \mathrm{P}<0.05,{ }^{\mathrm{c}} \mathrm{P}<0.01$ vs control.

same treatment conditions. Kojic acid, a well-known melanogenesis inhibitor, was used as a positive control ${ }^{[19]}$. [6]-Shogaol reduced melanin content in a dose-dependent manner (Figure 1B). Taken together, these results indicate that [6]-shogaol can inhibit melanin synthesis without any statistically significant cytotoxicity in B16 mouse melanoma cells.

[6]-Shogaol reduces intracellular tyrosinase activity in B16 cells, but does not affect mushroom tyrosinase activity in a cell-free system

To understand how [6]-shogaol regulates melanin synthesis in B16 cells, we studied the effect of [6]-shogaol on the activity of tyrosinase, one of the most critical factors for melanin synthesis. First, we treated B16 cells with [6]-shogaol at the indicated concentrations for $48 \mathrm{~h}$ and measured intracellular tyrosinase activities. We found that [6]-shogaol reduced intracelluar tyrosinase activity in a dose-dependent manner (Figure 2A). We further investigated whether [6]-shogaol directly affects tyrosinase activity using mushroom tyrosinase in a cellfree system. Interestingly, [6]-shogaol showed little inhibitory effect on mushroom tyrosinase activity, whereas kojic acid (a direct inhibitor of tyrosinase) had a significant inhibitory effect at $200 \mu \mathrm{mol} / \mathrm{L}$ (Figure 2B). Therefore, these results indicate that the inhibitory effect of [6]-shogaol on melanin synthesis is due to indirect regulation of intracellular tyrosinase activity rather than direct inhibition of tyrosinase activity.
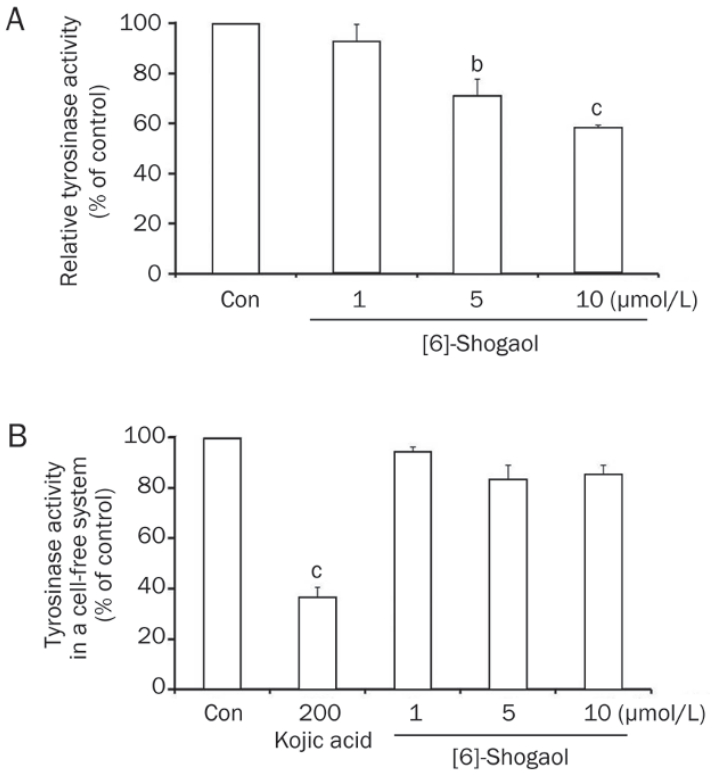

Figure 2. Effects of [6]-shogaol on tyrosinase activities. (A) Effect of [6]-shogaol on intracellular tyrosinase activity was studied after B16 cells were treated with [6]-shogaol at the indicated concentrations for $2 \mathrm{~d}$. (B) Direct effect of [6]-shogaol on tyrosinase activity was measured using mushroom tyrosinase in a cell-free system. Kojic acid was used as a positive control. Con, DMSO-only vehicle control. Data are reported as the mean \pm SEM of three independent experiments carried out in triplicate. ${ }^{\mathrm{b}} \mathrm{P}<0.05,{ }^{\mathrm{c}} \mathrm{P}<0.01$ vs control.

[6]-Shogaol decreases expression of tyrosinase and MITF in B16 cells

Several studies have shown that intracellular tyrosinase activity can be controlled by various mechanisms including the regulation of tyrosinase expression ${ }^{[26,27]}$. Therefore, we examined the effect of [6]-shogaol on the expression of both tyrosinase and MITF, the latter being a major transcription factor for tyrosinas $\mathrm{e}^{[5]}$. As shown in Figure 3A and 3B, the protein levels of tyrosinase and MITF were noticeably reduced by [6]-shogaol treatment in B16 cells.

[6]-Shogaol induces activation of the ERK pathway, but not the Akt pathway

It has been reported that many anti-pigmentation agents regulate tyrosinase and/or MITF expression through regulation of the MEK/ERK or the PI3K/Akt pathway ${ }^{[28,29]}$. Therefore, we examined the influence of [6]-shogaol on the ERK and Akt pathways in B16 cells. We treated B16 cells with DMSO as a control or with [6]-shogaol $(10 \mu \mathrm{mol} / \mathrm{L})$ for the indicated times. The activation of the ERK or the Akt pathway was determined by Western blotting using antibodies against specific phosphorylated forms of ERK or Akt. As shown in Figure 4, ERK phosphorylation was induced at $30 \mathrm{~min}$ and sustained until $4 \mathrm{~h}$ post-treatment by [6]-shogaol, compared with only a transient induction at $1 \mathrm{~h}$ post-treatment by DMSO. In contrast, Akt phosphorylation was gradually increased 
A

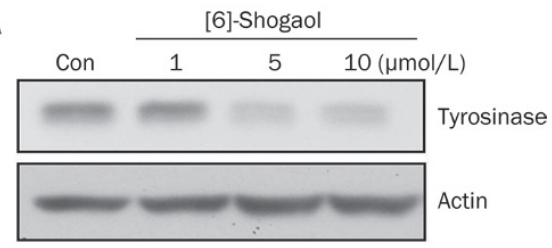

B

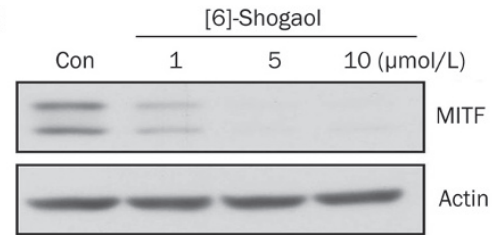

Figure 3. Effects of [6]-shogaol on protein expression of tyrosinase and MITF. B16 cells were treated with [6]-shogaol at the concentrations indicated above. (A) Tyrosinase expression and (B) MITF expression were analyzed at $48 \mathrm{~h}$ and $24 \mathrm{~h}$ after treatment, respectively, by Western blotting. Equal protein loading was confirmed using an anti-actin antibody. Con, DMSO-only vehicle control. Data shown are representative of three independent experiments.

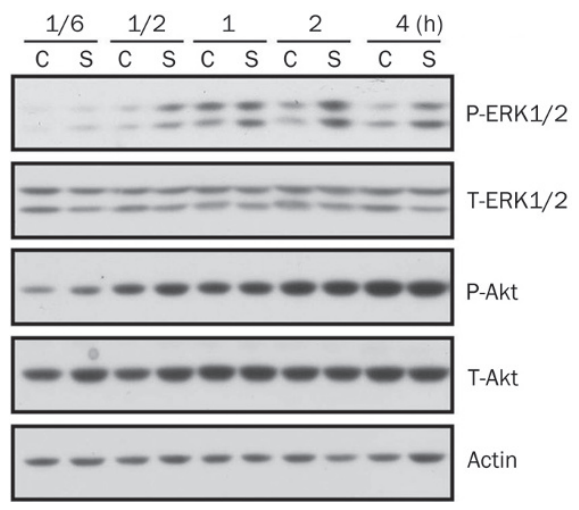

Figure 4. [6]-Shogaol induces activation of ERK, but not of Akt. B16 cells were treated with DMSO only or $10 \mu \mathrm{mol} / \mathrm{L}$ of [6]-shogaol for the indicated time. Whole cell lysates were then subjected to Western blot analysis using antibodies against phosphorylated or total forms of ERK1/2 and Akt. Equal protein loading was confirmed using an anti-actin antibody. C, DMSO only; S, [6]-shogaol. Data shown are representative of three independent experiments.

to the same extent by treatment with either DMSO-only or [6]-shogaol. These data indicate that [6]-shogaol can induce activation of the ERK pathway in B16 cells.

\section{Suppression of melanin synthesis by [6]-shogaol is attenuated by} inhibition of the ERK pathway

Because [6]-shogaol induced activation of the ERK pathway, we speculated whether the inhibitory effect of [6]-shogaol on melanin synthesis could be prevented by prior inhibition of the ERK pathway. Therefore, we pretreated B16 cells with DMSO or PD98059, a selective inhibitor of MEK (the upstream activator of ERK), for $1 \mathrm{~h}$ and then treated the cells with [6]-shogaol. As shown in Figure 5A, suppression of melanin synthesis by [6]-shogaol was greatly attenuated by the pretreatment with PD98059 (55\% inhibition in DMSO-treated cells vs $21 \%$ inhibition in PD98059-treated cells). We also found that the basal level of melanin was increased by the PD98059 treatment, which is consistent with previously published results ${ }^{[27]}$. In addition, [6]-shogaol-induced ERK phosphorylation was also inhibited by the PD98059 treatment (Figure 5B). These results indicate that [6]-shogaol-induced activation of the ERK pathway contributes to the inhibition of melanin synthesis in B16 cells.

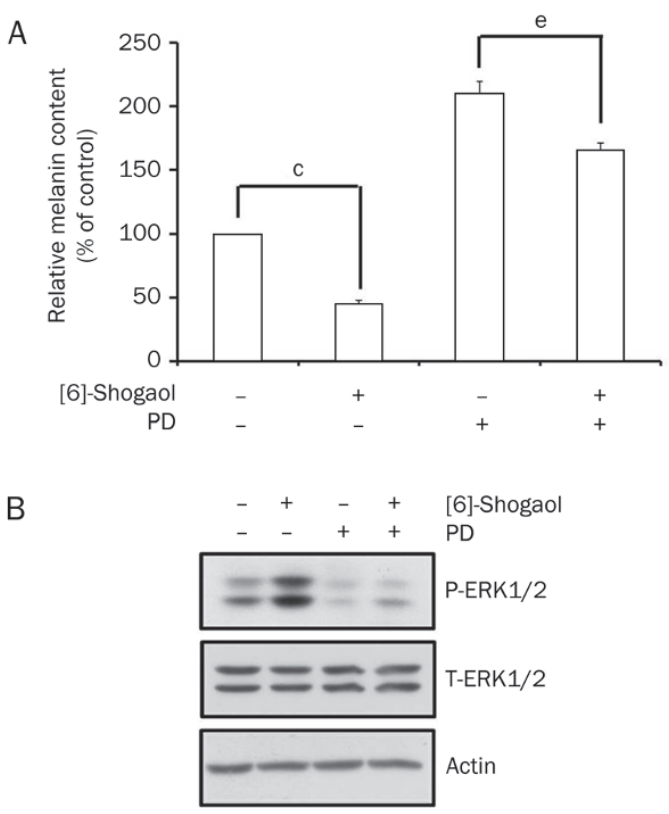

Figure 5. Suppression of the ERK pathway attenuates [6]-shogaol-induced inhibition of melanin synthesis. B16 cells were pretreated with DMSO only or PD98059 (20 $\mu \mathrm{mol} / \mathrm{L})$ for $1 \mathrm{~h}$, followed by the addition of [6]shogaol (10 $\mu \mathrm{mol} / \mathrm{L})$. (A) Relative melanin content was measured at $4 \mathrm{~d}$ after [6]-shogaol treatment. (B) ERK phosphorylation was examined at $4 \mathrm{~h}$ after [6]-shogaol treatment by Western blotting. Equal protein loading was confirmed by actin expression. PD, PD98059. Data are reported as the mean \pm SEM of three independent experiments carried out in triplicate. ${ }^{\mathrm{c}} P<0.01$ vs control. ${ }^{\mathrm{e}} P<0.05$ vs only PD98059 group.

\section{Discussion}

Ginger, the rhizome of the plant Zingiber, is consumed as a delicacy and spice worldwide. Moreover, it has long been used in traditional Chinese and Korean medicine as an anticancer agent ${ }^{[30]}$. Ginger can also decrease the pain from $\operatorname{arthritis}^{[31]}$ and protect against diarrhea ${ }^{[32]}$. [6]-Shogaol, one of the active ingredients in ginger, was identified to possess a surprisingly wide range of beneficial properties. It has been reported that [6]-shogaol can inhibit breast cancer cell invasion by reducing matrix metalloproteinase- 9 expression via the blockade of nuclear factor-kappaB activation ${ }^{[24]}$. [6]-Shogaol has also been shown to reduce chronic inflammatory response 
in the knees of rats treated with complete Freund's adjuvant ${ }^{[23]}$. However, despite many published results, the effect of [6]-shogaol on melanogenesis has not been reported. In the present study, we investigated the effect of [6]-shogaol on melanin synthesis and the molecular mechanism(s) involved in the process in B16 mouse melanoma cells.

First, we showed that [6]-shogaol inhibited melanin synthesis in a concentration-dependent manner without cytotoxicity (1-10 $\mu \mathrm{mol} / \mathrm{L})$ in B16 cells and that the extent of inhibition was comparable between treatment with [6]-shogaol ( $5 \mu \mathrm{mol} / \mathrm{L})$ and with kojic acid $(200 \mu \mathrm{mol} / \mathrm{L})$. Second, because tyrosinase is the key enzyme involved in melanogenesis ${ }^{[33,34]}$, we measured the effect of [6]-shogaol on tyrosinase activity. Interestingly, we found that [6]-shogaol decreased tyrosinase activity in B16 cells, but it did not affect mushroom tyrosinase activity in a cell-free assay system. Furthermore, we observed that [6]-shogaol decreased the expression of tyrosinase and MITF. MITF is widely known to control pigmentation by regulating the expression of melanogenic enzymes ${ }^{[4,35]}$.

The ERK pathway regulates cell proliferation and differentiation in many types of cells ${ }^{[36,37]}$. This pathway is also involved in the regulation of melanin synthesis. It has been reported that activation of MEK/ERK leads to phosphorylation of MITF at serine 73, resulting in its degradation ${ }^{[28,38]}$. The PI3K/Akt pathway plays an important role in cell growth regulation and apoptosis inhibition ${ }^{[39,40]}$. In addition, activation of the PI3K/Akt pathway reduces tyrosinase transcription and melanogenesis in B16F10 cells ${ }^{[17,29]}$. So far, many natural and synthetic agents have been found to inhibit melanogenesis in B16F10 cells through activation of the ERK and/or the Akt pathways. For example, baicalein, cimicifuga heracleifolia, and KHG22394 (a synthesized chemical) were found to decrease melanin synthesis by activating ERK or $\mathrm{Akt}^{[18,26,27]}$. Therefore, we are interested in the effects of [6]-shogaol on ERK and Akt activities. We found that [6]-shogaol induced ERK but not Akt activation. Moreover, the suppressive effect of [6]-shogaol on melanin synthesis was diminished by a prior inhibition of the ERK pathway. These results suggest that ERK activation by [6]-shogaol plays an important role in the compound's anti-melanogenic effect in B16 cells. However, our results also indicate that there may be other pathway(s) involved in the inhibition of melanin synthesis by [6]-shogaol because the anti-melanogenic effect of [6]-shogaol was not completely abrogated by the inhibition of the ERK pathway. Further studies are needed in order to elucidate the pathway(s).

In summary, in this study we investigated the antimelanogenic effect of [6]-shogaol and the underlying mechanisms in B16 mouse melanoma cells. We found that [6]-shogaol possesses a desirable ability to inhibit melanin synthesis by activation of the ERK pathway and by inhibition of tyrosinase production.

\section{Acknowledgements}

This work was supported by the Basic Science Research Program through the National Research Foundation of Korea
(NRF) funded by the Ministry of Education, Science and Technology (2010-0008196).

\section{Author contribution}

Cheng YAO, Chi-hyun PARK and Jin Ho CHUNG designed research; Cheng YAO, Jang-hee $\mathrm{OH}$ and Inn Gyung $\mathrm{OH}$ performed research; Cheng YAO, Chi-hyun PARK and Jin Ho CHUNG analyzed data; Chi-hyun PARK and Jin Ho CHUNG wrote the paper.

\section{References}

1 Boissy RE. Melanosome transfer to and translocation in the keratinocyte. Exp Dermatol 2003; 12: 5-12.

2 Ortonne JP, Ballotti R. Melanocyte biology and melanogenesis: what's new? J Dermatol Treat 2000; 11: S15-6.

3 Yaar M, Gilchrest BA. Melanocyte biology: before, during, and after the Fitzpatrick era. J Invest Dermatol 2004; 122: xxvii-xxix.

4 Bentley NJ, Eisen T, Goding CR. Melanocyte-specific expression of the human tyrosinase promoter: activation by the microphthalmia gene product and role of the initiator. Mol Cell Biol 1994; 14: 7996-8006.

5 Yasumoto K, Yokoyama K, Takahashi K, Tomita Y, Shibahara S. Functional analysis of microphthalmia-associated transcription factor in pigment cell-specific transcription of the human tyrosinase family genes. J Biol Chem 1997; 272: 503-9.

6 Bertolotto C, Busca R, Abbe P, Bille K, Aberdam E, Ortonne JP, et al. Different cis-acting elements are involved in the regulation of TRP1 and TRP2 promoter activities by cyclic AMP: pivotal role of $M$ boxes (GTCATGTGCT) and of microphthalmia. Mol Cell Biol 1998; 18: 694702.

7 Gilchrest BA, Park HY, Eller MS, Yaar M. Mechanisms of ultraviolet light-induced pigmentation. Photochem Photobiol 1996; 63: 1-10.

8 Yamaguchi Y, Hearing VJ. Physiological factors that regulate skin pigmentation. Biofactors 2009; 35: 193-9.

9 Englaro W, Rezzonico R, Durand-Clement M, Lallemand D, Ortonne JP, Ballotti R. Mitogen-activated protein kinase pathway and AP-1 are activated during CAMP-induced melanogenesis in B-16 melanoma cells. J Biol Chem 1995; 270: 24315-20.

10 Imokawa G, Yada Y, Kimura M. Signalling mechanisms of endothelininduced mitogenesis and melanogenesis in human melanocytes. Biochem J 1996; 314: 305-12.

11 Miyamura Y, Coelho SG, Wolber R, Miller SA, Wakamatsu K, Zmudzka $\mathrm{BZ}$, et al. Regulation of human skin pigmentation and responses to ultraviolet radiation. Pigment Cell Res 2007; 20: 2-13.

12 Yamaguchi Y, Brenner M, Hearing VJ. The regulation of skin pigmentation. J Biol Chem 2007; 282: 27557-61.

13 Ganesan AK, Ho H, Bodemann B, Petersen S, Aruri J, Koshy S, et al. Genome-wide siRNA-based functional genomics of pigmentation identifies novel genes and pathways that impact melanogenesis in human cells. PLoS Genet 2008; 4: e1000298.

14 Busca R, Bertolotto C, Ortonne JP, Ballotti R. Inhibition of the phosphatidylinositol 3-kinase/p70(S6)-kinase pathway induces B16 melanoma cell differentiation. J Biol Chem 1996; 271: 31824-30.

15 Oka M, Nagai H, Ando H, Fukunaga M, Matsumura M, Araki K, et al. Regulation of melanogenesis through phosphatidylinositol 3-kinaseAkt pathway in human G361 melanoma cells. J Invest Dermatol 2000; 115: 699-703.

16 Kim DS, Kim SY, Chung JH, Kim KH, Eun HC, Park KC. Delayed ERK activation by ceramide reduces melanin synthesis in human melanocytes. Cell Signal 2002; 14: 779-85.

17 Khaled M, Larribere L, Bille K, Ortonne JP, Ballotti R, Bertolotto C. 
Microphthalmia associated transcription factor is a target of the phosphatidylinositol-3-kinase pathway. J Invest Dermatol 2003; 121 : 831-6.

18 Li X, Guo L, Sun Y, Zhou J, Gu Y, Li Y. Baicalein inhibits melanogenesis through activation of the ERK signaling pathway. Int J Mol Med 2010; 25: 923-7.

19 Sehgal VN, Verma P, Srivastava G, Aggarwal AK, Verma S. Melasma: treatment strategy. J Cosmet Laser Ther 2011; 13: 265-79.

20 Boissy RE, Visscher M, DeLong MA. DeoxyArbutin: a novel reversible tyrosinase inhibitor with effective in vivo skin lightening potency. Exp Dermatol 2005; 14: 601-8.

21 Serra-Baldrich E, Tribo MJ, Camarasa JG. Allergic contact dermatitis from kojic acid. Contact Dermatitis 1998; 39: 86-7.

22 O'Donoghue JL. Hydroquinone and its analogues in dermatology - a risk-benefit viewpoint. J Cosmet Dermatol 2006; 5: 196-203.

23 Levy AS, Simon 0, Shelly J, Gardener M. 6-Shogaol reduced chronic inflammatory response in the knees of rats treated with complete Freund's adjuvant. BMC Pharmacol 2006; 6: 12.

24 Ling $\mathrm{H}$, Yang $\mathrm{H}$, Tan SH, Chui WK, Chew EH. 6-Shogaol, an active constituent of ginger, inhibits breast cancer cell invasion by reducing matrix metalloproteinase-9 expression via blockade of nuclear factorkappaB activation. Br J Pharmacol 2010; 161: 1763-77.

25 Smalley K, Eisen T. The involvement of p38 mitogen-activated protein kinase in the alpha-melanocyte stimulating hormone (alpha-MSH)induced melanogenic and anti-proliferative effects in B16 murine melanoma cells. FEBS Lett 2000; 476: 198-202.

26 Kim DS, Jeong YM, Park IK, Hahn HG, Lee HK, Kwon SB, et al. A new 2-imino-1,3-thiazoline derivative, KHG22394, inhibits melanin synthesis in mouse B16 melanoma cells. Biol Pharm Bull 2007; 30: 180-3.

27 Jang JY, Lee JH, Kang BW, Chung KT, Choi YH, Choi BT. Dichloromethane fraction of Cimicifuga heracleifolia decreases the level of melanin synthesis by activating the ERK or AKT signaling pathway in B16F10 cells. Exp Dermatol 2009; 18: 232-7.

28 Wu M, Hemesath TJ, Takemoto CM, Horstmann MA, Wells AG, Price ER, et al. c-Kit triggers dual phosphorylations, which couple activation and degradation of the essential melanocyte factor Mi. Genes Dev 2000; 14: 301-12.

29 Khaled M, Larribere L, Bille K, Aberdam E, Ortonne JP, Ballotti R, et al. Glycogen synthase kinase 3beta is activated by cAMP and plays an active role in the regulation of melanogenesis. J Biol Chem 2002; 277: 33690-7.

30 Vimala S, Norhanom AW, Yadav M. Anti-tumour promoter activity in Malaysian ginger rhizobia used in traditional medicine. $\mathrm{Br} J$ Cancer 1999; 80: 110-6.

31 Srivastava KC, Mustafa T. Ginger (Zingiber officinale) and rheumatic disorders. Med Hypotheses 1989; 29: 25-8.

32 Ghayur MN, Gilani AH. Pharmacological basis for the medicinal use of ginger in gastrointestinal disorders. Dig Dis Sci 2005; 50: 1889-97.

33 del Marmol V, Beermann F. Tyrosinase and related proteins in mammalian pigmentation. FEBS Lett 1996; 381: 165-8.

34 Inagaki $\mathrm{H}$, Bessho $\mathrm{Y}$, Koga $\mathrm{A}$, Hori $\mathrm{H}$. Expression of the tyrosinaseencoding gene in a colorless melanophore mutant of the medaka fish, Oryzias latipes. Gene 1994; 150: 319-24.

35 Gaggioli C, Busca R, Abbe P, Ortonne JP, Ballotti R. Microphthalmiaassociated transcription factor (MITF) is required but is not sufficient to induce the expression of melanogenic genes. Pigment Cell Res 2003; 16: 374-82.

36 Cowley S, Paterson H, Kemp P, Marshall CJ. Activation of MAP kinase kinase is necessary and sufficient for PC12 differentiation and for transformation of NIH 3T3 cells. Cell 1994; 77: 841-52.

37 Sale EM, Atkinson PG, Sale GJ. Requirement of MAP kinase for differentiation of fibroblasts to adipocytes, for insulin activation of p90 S6 kinase and for insulin or serum stimulation of DNA synthesis. EMBO J 1995; 14: 674-84.

38 Goodall J, Carreira S, Denat L, Kobi D, Davidson I, Nuciforo P, et al. Brn-2 represses microphthalmia-associated transcription factor expression and marks a distinct subpopulation of microphthalmiaassociated transcription factor-negative melanoma cells. Cancer Res 2008; 68: 7788-94.

39 Ahmad S, Singh N, Glazer RI. Role of AKT1 in 17beta-estradioland insulin-like growth factor I (IGF-I)-dependent proliferation and prevention of apoptosis in MCF-7 breast carcinoma cells. Biochem Pharmacol 1999; 58: 425-30.

40 Tang Y, Zhou H, Chen A, Pittman RN, Field J. The Akt proto-oncogene links Ras to Pak and cell survival signals. J Biol Chem 2000; 275: 9106-9. 